\title{
Cesare Pavese en España: La antología poética de 1971
}

\author{
José ABAD \\ Universidad de Granada \\ joseabad@ugr.es
}

\section{Resumen}

Este trabajo analiza el corpus poético seleccionado por José Agustín Goytisolo para su famosa Antología de la poesía de Cesare Pavese, publicada en Barcelona, en 1971, por Seix Barral. Este estudio pone de manifiesto cómo la selección del poeta español falsea en cierto modo la actividad poética del gran escritor italiano. Ya que a través del corpus pavesiano escogido por Goytisolo para su antología, se favorece casi exclusivamente una imagen del escritor piamontés más acorde con el tono sentimental y decadente, en detrimento de su vertiente más realista, incómoda o si se prefiere "revolucionaria", con respecto a los parámetros del hermetismo lírico imperante en la Italia en los años 30 del siglo pasado.

Palabras clave: Antología de poesía, Cesare Pavese, José Agustín Goytisolo, comparatismo.

\section{Cesare Pavese in Spain. The 1971 anthology of poetry}

\begin{abstract}
This work analyzes the corpus of poetry selected by José Agustín Goytisolo in his famous Anthology of Cesare Pavese's poems, published in Barcelona in 1971 by Seix Barral. This study demostrates that the selection made by the Spanish poet falsifies the activity of the great Italian writer because the corpus chosen by Goytisolo favours an emotional and decadent image of Pavese. The Goytisolo's anthology avoids his more realistic, annoying and "revolutionary" aspect, according with the lyrical parameters of the Italian ermetismo, the prevailing movement of poetry in Italy in the thirties.
\end{abstract}

Key words: Anthology of poetry, Cesare Pavese, José Agustín Goytisolo, comparatism.

Abad, José, 2011. Cesare Pavese en España: La antología poética de 1971. Cuadernos de Filología Italiana, $\mathrm{n}^{\mathrm{o}}$ extraodinario: págs 13-20. 
En principio, me serviré de cifras. Si sumamos las composiciones de Lavorare stanca a las de Poesie del disamore -los dos volúmenes que en la actualidad reúnen idealmente los versos del piamontés-, tendremos unos ciento veinte poemas; ciento veintitrés, para ser exactos. La Antología poética, en edición bilingüe, preparada por José Agustín Goytisolo y publicada por Plaza \& Janés en 1971, ofreció al lector español de entonces cuarenta de estos poemas, ni uno más ni uno menos. O sea, una tercera parte del corpus poético pavesiano. Una proporción mayor, pues, si atendemos a lo que el propio Goytisolo afirmaba en el prólogo, habría hecho su selección exclusivamente a partir de Lavorare stanca (1943) y Verrà la morte e avrà i tuoi occhi (1951), «los dos únicos libros de poesía escritos por Cesare Pavese -escribió-: los veintitrés primeros pertenecen al libro Lavorare stanca [...]. De su segundo libro: Verrà la morte e avrà i tuoi occhi, he seleccionado diecisiete poemas» (Pavese, 1971: $15-16^{1}$ ). Goytisolo habría descartado la poesía dispersa, en beneficio de la recogida en dos poemarios bien definidos -el segundo de ellos, téngase en cuenta, editado póstumamente-, lo que excluye del cálculo inicial treinta y tres de los treinta y cuatro poemas ahora agrupados en los siguientes epígrafes ${ }^{2}$ :

- Poesie del disamore (1934-1938)

- Altre poesie degli anni (1931-1940)

- Due poesie (1946)

Sigamos con las cifras. Si nos centramos en los dos poemarios tomados en consideración, encontramos que Goytisolo eligió treinta y nueve del total de noventa poemas que suman ambos libros; prácticamente, la mitad de lo que él consideraba la poesía completa de Pavese. Lo que querría señalar con este preámbulo matemático es que la Antología de 1971 ofreció una amplia panorámica de la poesía pavesiana y que el lector español pudo hacerse (o pudiera haberse hecho) una buena idea de ella. Una panorámica amplia, empero parcial. No digo "tendenciosa", sino "parcial". No me cabe la menor duda de que la antología satisfizo con creces su principal objetivo; esto es, presentar al escritor piamontés en España (de hecho fue un libro fundamental para dar a conocer a Pavese ${ }^{3}$. Y sin embargo, resulta llamativo lo que esta antología tiene de interesada, además de interesante. Pero vayamos poco a poco.

${ }^{1}$ Lavorare stanca se publicó por primera vez en 1936 en Florencia, Edizioni di Solaria. El libro estaba compuesto entonces por cuarenta y cinco poesías de las cuales se mantuvieron treinta y nueve en la edición definitiva de Einaudi (1943). En 1936, por problemas con la censura, Pavese debió eliminar cuatro poesías, luego recuperadas. (Estas poesías son: Il dio-caprone, Pensieri di Deola, Balleto y Paternità). En cuanto a Verrà la morte e avrà i tuoi occhi, sería publicado por Einaudi en 1951, póstumo. La Antología poética de Plaza \& Janés está dividida en dos partes tituladas precisamente así: 1) de Trabajar cansa y 2) de Vendrá la muerte y tendrá tus ojos.

2 He dicho «treinta y tres de los treinta y cuatro poemas», pues de los veintitrés poemas incluidos en la primera parte, el último de ellos no pertenece a Lavorare stanca. Sucede que Goytisolo puso como colofón de esta primera parte el poema La casa -hoy, al final de Altre poesie degli anni 1931-1940-, aunque esta pieza apareció en Verrà la morte e avrà i tuoi occhi, en su edición de 1951.

${ }^{3}$ Cabe deducir la enorme repercusión de esta Antología poética por los errores a que indujo. En su edición del poemario Troppo mare de Javier Egea, José Rienda afirmaba, equivocadamente: «Troppo mare son las dos palabras iniciales del primer libro de poemas de Cesare Pavese, Lavorare stanca» (Egea, 2000: 29). En fin, éstas no son las palabras iniciales del primer libro de Pavese, sino las del poema que Goytisolo colocó en primer lugar en la antología. 
Y empecemos por el final.

No tiene sentido hablar de "manipulación" en el bloque dedicado a Verrà la morte e avrà i tuoi occhi. Goytisolo recoge íntegramente los poemas de la sección La terra e la morte y todos, excepto dos, de Verrà la morte... propiamente dicha. Quedan fuera solo dos composiciones escritas en inglés, con toda seguridad, precisamente por estar en inglés; nos referimos a To C. from C. y Last blues, to be read some day. Así las cosas, no acabamos de entender a qué se refiere Goytisolo en el prólogo cuando afirma: «se han seleccionado los ocho [poemas] que he considerado como más representativos, y como de mayor calidad» (Pavese, 1971: 17). Nada de «poemas-más-representativos». No hubo «selección» como pretende dar a entender el traductor y antólogo. Goytisolo juega al despiste pues, como digo, ofrece íntegra (o casi) una obra magnífica. Una decisión nada casual que, según veremos, tendrá sus consecuencias.

Ahora podemos dar un paso atrás, irnos al principio de la antología, y centrar nuestra atención en los veintidós poemas que Goytisolo entresacó de Lavorare stan$c a^{4}$. Aquí se hace patente esa sutil parcialidad que he señalado: de las seis partes que componen este extenso poemario (setenta poemas en total), a Goytisolo le interesan principalmente las dos primeras: Antenati y Dopo (Goytisolo, como poco, habría podido ser más ecuánime con la disposición de Pavese, pero...).

El tema de la primera parte es la vida en el campo. Sorprendentemente (o no, como iremos viéndolo), Goytisolo prescindió de los dos primeros poemas, I mari del Sud y el que da título a este bloque, Antenati. Y digo "sorprendentemente" porque Goytisolo no podía ignorar la importancia decisiva que I mari del Sud tuvieron en la evolución poética del piamontés ${ }^{5}$. Cualquier acercamiento riguroso a la poesía de Pavese tendría que rendir un tributo obligatorio a esta extraordinaria composición, y que Goytisolo no lo hiciera repercute negativamente en su antología, ya que ésta no cumple el cometido "informativo" que le presuponemos a un trabajo de esta naturaleza. Debo confesar que esta ausencia fue el detonante de estas pocas páginas. ¿Por qué descartar un poema fundamental como I mari del Sud? ¿Por qué prescindir de Antenati? Una de las primeras conclusiones que me atrevería a ofrecer es que a Goytisolo le interesaba el poeta tanto como su poesía. Volveré sobre este punto.

La Antología comienza con un poema menos drástico, menos inconveniente que los descartados, Gente spaesata, sobre el tema del desarraigo. Los seis poemas seleccionados de esta primera parte conforman un retrato objetivo de un mundo de extrema dureza. Pensemos en la mujer embarazada a quien sorprenden los dolores

\footnotetext{
${ }^{4}$ El poema vigésimo tercero de este primer bloque, La casa, insisto, se incluyó por su pertenencia ideal, no real, al ciclo.

${ }^{5}$ En el prefacio a la edición de las poesías completas manejada por José Agustín Goytisolo, Massimo Mila escribía: «Anche cronologicamente, I mari del Sud è davvero la prima delle poesie di Lavorare stanca, e messa lì al principio viene spesso considerata come un terminus a quo, come un punto de partenza che in seguito la poesia de Pavese si lascia alle spalle per inoltrarsi entro piú segrete rive. Invece I mari del Sud è un punto d'arrivo. La precedono decine, forse centinaia di poesie ripudiate, che Pavese leggeva agli amici nello studio dell'amico pittore, nei cheti caffè di via Pò, nelle osterie in collina, senza mai riuscire a persuadere interamente né loro né se stesso» (Pavese, 1962: VII).
} 
del parto trabajando en la era (en el poema Il figlio della vedova) o en la mujer que contempla el cuerpo del marido muerto en medio del campo (Luna d'agosto) o en los campesinos que ven cómo la escarcha destruye su cosecha (Gente che c'è stata). Son estampas crudas en las que domina lo telúrico, aunque también lo feérico tenga un hueco, si bien mínimo; pensemos ahora en la estampa de unos perros lanzados tras el rastro del macho cabrío que, según imagina Pavese, bailan puestos en pie en medio del bosque mientras ladran a la luna (Il dio-caprone). Se incluye asimismo $\mathrm{La}$ notte, una pieza que evoca un recuerdo vago de un niño que contempla la noche sobre las colinas, «la notte sui colli».

La pregunta es: ¿Qué deja fuera de esta primera parte? ¿Tienen algo en común los cinco poemas de Antenati descartados? Algo hay: son poemas con aspectos locales más acentuados. Cabría pensar, entonces, que con muy buen juicio Goytisolo eligió sólo aquellos textos que despertarían una cierta identificación con un mundo rural de cuatro décadas atrás, el de la Italia de los años 30, muy similar al de la España de 1971. (E incluso al mundo rural español de hace relativamente poco, pero esta es otra historia). Se dejan fuera los tres poemas de la serie Paesaggio, una decisión que arrastra consigo el resto de poemas de dicha serie repartidos por el libro. Y también se excluyen varias composiciones, llamémoslas incómodas... Yo insistiría en Antenati, un poema en el que Pavese despliega una misoginia ostentosa y un culto a la virilidad pertenecientes a una veta de "primitivismo" muy presente en este autor. En el prólogo a La literatura norteamericana y otros ensayos, Italo Calvino escribió:

El primitivismo, lo bárbaro, el culto de lo salvaje y lo inconsciente son en la cultura occidental un «mal del siglo», de los más llamativos y difíciles de eludir. Pavese vivió sumido en esta problemática, siempre en primera línea, a menudo en áreas polémicas, muy controvertidas, ora desafiante, ora retrocediendo (Calvino, 2008: 16). (Veremos que efectivamente es así).

La segunda parte, Dopo, gira en torno al amor y al sexo. Está compuesta por quince poemas, de los que Goytisolo toma ocho, más de la mitad. Los cinco primeros son ejemplos magníficos del Pavese más emotivo, ese "poeta sentimental" que acabará imponiéndose en la antología gracias a los versos de Verrà la morte e avrà i tuoi occhi. Pensemos en la ternura sin subrayados de los poemas Incontro o Estate; pensemos en la soledad («viril», gustaba de adjetivar Pavese) del poema Mania di solitudine; pensemos en el recuerdo de cuando joven se quedó absorto ante la donna ridente (Rivelazione) o en esa magnífica marina de mujeres que bajan al mar a bañarse con el caer de la tarde (Donne appassionate). Las tres estampas de prostitutas (Tolleranza, La puttana contadina o Due sigarette) podrían añadirse al cuadro social de los poemas iniciales de la antología.

La pregunta vuelve a ser: ¿qué desecha?

Pues se quedan fuera varias piezas discretas, melancólicas: Mattino, Notturno o la que da título al bloque Dopo. Se arrincona, inevitablemente, Paesaggio VII. También una pieza muy sugerente, Terre bruciate, que suma el tema del confinamiento al tema sexual al presentar la estampa de unos hombres que, en Il confino, compa- 
ran a las mujeres del Norte de Italia con las del Sur, y que cabría meter en el mismo saco de otras piezas misóginas. Y repudia asimismo Pensieri di Deola, uno de los poemas más hermosos de cuantos Pavese escribió con prostitutas como protagonistas, quizás más local que esos otros que Goytisolo sí mantuvo en la Antología (repito: Tolleranza, La puttana contadina, Due sigarette). También queda fuera Agonia, un poema puesto en labios de una mujer y quizás por ello eliminado. Si le interesaba el poeta tanto como su poesía, según he apuntado, Goytisolo quería el "yo" de Cesare Pavese; el desdoblamiento desvirtuaría el retrato. Agonia es una pieza hermosa, terrible, en la que se escuchan los pensamientos de una joven suicida, aunque del suicidio apenas quede nada en los versos; sólo en el título.

De los cuatro bloques restantes, Goytisolo tomará dos poemas de cada uno, que insisten en los dos temas ya fijados (quizás "prefijados") en el momento de decantarse por las dos primeras partes de Lavorare stanca: lo social y lo sentimental. Se diría que para no empañar la imagen de "Pavese, hombre comprometido" o de "Pavese, hombre sentimental" lo más conveniente era eliminar la misoginia de los poemas Antenati o Terre bruciate. La imagen de Pavese que Goytisolo está construyendo, no importa si consciente o inconscientemente, habría quedado seriamente dañada de haber mantenido ambas piezas. Tal como está ideada, en la Antología habrían desentonado versos como:

E le donne non contano nella famiglia.

Voglio dire, le donne da noi stanno in casa

e ci mettono al mondo e non dicono nulla

e non contano nulla e non le ricordiamo (Antenati, vv. 29-32) ${ }^{6}$.

Del tercer bloque, Città in campagna, el más nutrido y variado del libro, toma el poema sobre un niño que se parte la espalda al caerse de un tejado (Avventure) y el del hombre solo en busca una compañera para hacer frente a las fatigas de la vida (Lavorare stanca), que responden idealmente al ámbito de lo social, aunque en el último yazca un intenso poso sentimental. De la cuarta parte, Maternità, rescata otros dos poemas: Piaceri notturni y La voce, que se relacionan muy bien con el poema inmediatamente anterior, Lavorare stanca, por su ambientación nocturna y por el elemento pasional. (Goytisolo, hay que aplaudírselo, creó una muy eficaz continuidad entre las piezas elegidas).

En el quinto bloque, Legna verde, cuyo tema común es la política, Goytisolo actúa con prudencia y se decide por los dos textos menos radicales, lo suficientemente abstractos como para sortear cualquier posible suspicacia en la España de la época: Una generazione y Parole del politico, el segundo de los cuales, escrito durante el confinamiento en Brancaleone, prepara el terreno a las dos últimas piezas de la antología - pertenecientes al sexto bloque, Paternità-, dos magníficas composiciones en torno a la idea de la espera: Il paradiso sui tetti y Semplicità ${ }^{7}$. La selec-

\footnotetext{
6 Citaré siempre por Cesare Pavese (1962).

7 Estamos analizando la labor del antólogo, no la del traductor. En líneas generales, la traducción es aceptable, pero en Semplicità hay varias inexactitudes y algún pasaje que Goytisolo no comprendió bien.
} 
ción acaba con La casa, que no pertenece a Lavorare stanca, pero en la que se escucha el tema recurrente del hombre solitario, l'uomo solo, planteado antes en Semplicità (y presente en L'istinto, Paternità y Lo steddazzu, no incluidos en la antología). Me atrevería a decir que La casa, al darse una reconciliación con el mundo, casi pone un final feliz a esta primera parte.

A propósito de los cuatro últimos bloques de Lavorare stanca no tendría sentido preguntarse qué queda fuera, pues es prácticamente todo. Y sin embargo, debemos hacernos esta pregunta. Nos la hacemos. Y lo que descubrimos es cuando menos curioso. Queda fuera, una vez más, una pieza que santifica lo viril y coloca a la mujer, en precario equilibrio, entre la atracción y la repulsa, Balletto:

[...] La donna non conta, ogni sera è diversa, ma sempre una piccola che ridendo contiene il culetto che danza (vv. 8-10).

La misoginia es un motivo insistente en Pavese, pero no un capítulo cerrado. A veces, el estribillo la donna non conta se utiliza para poner en entredicho la prepotencia masculina, aunque de manera quizás ambigua, como ocurre en Maternità -que Goytisolo también descartó-, un poema que habla de «esa mujer que no cuenta», que ya no está, pero que es a quien deben la vida los varones del poema. Los versos que nos interesan dicen así:

Dalle membra del padre (la donna non conta)

debbon esser usciti, già fatti, tre giovani

come lui (vv. 4-6).

Así pues, queda fuera el elemento misógino. El poeta de lo primitivo ha sido civilizado, al menos en parte. Y se queda fuera o apenas se ofrecen muestras del poeta de la memoria, el hombre que interroga al mito, el individuo más insolente y politizado (el de Fumatori di carta), etc. El trabajo de limadura no debiera pasarse por alto; se han eliminado contrastes de una manera manifiesta. Parto de mi experiencia como lector: Leo Lavorare stanca y encuentro un poeta problemático y unos versos plagados de aristas; leo la Antología poética y me encuentro, en cambio, con un poeta magnífico, pero cabal, y unos versos intensos, pero devastados.

Al hacer una antología, las omisiones son inevitables. No obstante, cuando la obra no es extensa -sino intensa, como la de Pavese-, es relativamente fácil estudiar tales omisiones. Gracias a los poemas elegidos de Lavorare stanca y a la decisión de mantener intacto Verrà la morte e avrà i tuoi occhi, Goytisolo privilegia al poeta melancólico en detrimento del primitivo, y concede igual espacio al poeta subjetivo que al objetivo. La poesía de Cesare Pavese, según la antología de 1971, pivota en torno a dos ejes bien definidos: lo social y lo sentimental. Al final del prólogo, Goytisolo se hace eco de una anotación de Il mestiere de vivere, correspondiente al 15 de septiembre de 1936; en él, Pavese confesaba: «Io non so ancora se sono un poeta o un sentimentale...» (Pavese, 1999: 45). Pues bien, se diría que Goytisolo hubiera 
decidido tomar cartas en el asunto y responderle afirmativamente: «Sí, eres un poeta. Y sí, eres un sentimental».

¿Algunas conclusiones? En cualquier estudio sobre la recepción de Cesare Pavese en España, en primer lugar, habrá que subrayar la preeminencia del poeta en perjuicio del narrador y, en segundo lugar, la idealización de su figura, todo lo bienintencionada que se quiera, pero incuestionable. Una figura adornada con la aureola romántica del suicidio, la soledad incurable, la melancolía, el interés por los desahuciados, etc. La Antología poética avivó las luces de lo pasional para ahuyentar las sombras más incómodas. Al actuar de este modo, se olvida que la pérdida de contrastes, aunque la intención sea adecentar al escritor, conlleva el empobrecimiento de su obra.

La culpa quizás la tengan las antologías ${ }^{8}$.

Las antologías tienden a verse como "apéndices" de un cuerpo mayor. Su "esencia", dirán algunos. "Residuos", dirán otros. En realidad, hablamos de "fragmentos" de una obra más amplia que al ser descontextualizados y reordenados pueden adquirir y, de hecho, adquieren un sentido nuevo. Hay que perseverar en la vieja polémica de que las antologías forman un género en sí mismo, pertinazmente instrumentalizado, y que es más útil estudiarlas en función del autor (o sea, el responsable de la antología) o de su circunstancia histórica (el momento, el lugar de su edición) que en relación al autor antologado, aunque este jamás sea un simple convidado de piedra, por descontado.

La antología "de" Cesare Pavese "de" José Agustín Goytisolo explica al primero tanto como al segundo. La materia prima la suministró Pavese, por supuesto, pero se privilegiaron los aspectos más atractivos para José Agustín Goytisolo, también poeta, sentimental y comprometido; también suicida. Se privilegiaron, asimismo, los aspectos más urgentes para una sociedad necesitada de ejemplos. Goytisolo modeló al poeta más útil, sin duda, para la España de los 70 del pasado siglo. De todos modos, la impresión última es que la Antología poética de 1971 es más interesante como obra en sí que como destilación o compendio de la poesía pavesiana.

Si estamos en lo cierto, algo esencial se perdió en el camino.

\section{Bibliografía}

CALvino, Italo (2008): «Introducción» a La literatura norteamericana y otros ensayos. Barcelona, Lumen, pp. 9-33.

EgEA, Javier (2000): Troppo Mare, ed. José Rienda. Granada, Dauro.

MiLA, Massimo (1962): «Prefazione» a Poesie (Lavorare stanca, Verrà la morte e avrà i tuoi occhi). Torino, Einaudi.

PAVESE, Cesare (1962): Poesie.Torino, Einaudi.

\footnotetext{
8 En el caso de Lavorare stanca, además, no se trata de una simple recopilación de poemas, sino de una obra orgánica a la manera de Hojas de hierba de Walt Whitman o Antología de Spoon River de Edgar Lee Masters, muy admiradas por el propio Pavese. En estos casos, cualquier reducción conlleva inevitablemente una pérdida significativa.
} 
PAVESE, Cesare (1971): Antología poética. Barcelona, Plaza \& Janés.

PAVESE, Cesare (1999): Il mestiere di vivere. Torino, Einaudi.

PAVESE, Cesare (2008): La literatura norteamericana y otros ensayos. Barcelona, Lumen. 